\title{
Seismic isolation and energy dissipation: worldwide application and perspectives
}

\author{
A. Martelli \\ ENEA, Bologna, Italy
}

\begin{abstract}
At present there are approximately 5,000 structures in the world which are protected by seismic isolation (SI), energy dissipation (ED) and other modern seismic vibration passive control (SVPC) systems, such as shock transmitters (STs) and shape memory alloy devices (SMADs), and the number of such applications is increasing more and more. The conclusive influence of the features of the design rules used on the extension of application of the SVPC systems is evident. With regard to such an application, Japan has consolidated its worldwide leadership, with over 3,000 seismically isolated buildings in October 2006 and many others protected by ED systems. The Russian Federation remains second for the number of isolated buildings (550 in June 2005). Third, with 490 isolated buildings, is the P.R. China. In the USA, due to the very penalizing design code in force for SI of buildings, there are now only a few new applications of this kind (their overall number is approximately 200, although they are mostly quite important, half being retrofits). At present Italy (which is still worldwide leader as to SVPC application to bridges and viaducts) remains fifth for the number of isolated buildings already opened to activity: 43, besides 19 protected by ED or SMADs and 28 by STs. However, there is a significant increase of the number of Italian building applications of the SVPC systems completed in the last two years and of that of new projects: this occurred thanks to the new national seismic code, enforced in May 2003. As to other countries, of note are the growing use of SVPC in Taiwan and of SI of buildings in Armenia and New Zealand. Furthermore, important applications also began in Turkey, Greece, Portugal and Cyprus (many thanks to devices manufactured in Italy) and are going on in France (in particular in La Martinique island) and Chile. To be stressed are also the increasing use of SI for liquefied natural gas tanks and nuclear structures and the already significant application of the SVPC to cultural heritage, especially in Italy.

Keywords: passive control of vibrations, seismic isolation, energy dissipation, shape memory alloys, shock transmitters, seismic retrofit, buildings, bridges and viaducts, cultural heritage, liquefied natural gas tanks, nuclear reactors.
\end{abstract}




\section{Introduction}

At present, there are approximately 5,000 structures in the world that are protected by seismic isolation (SI), energy dissipation (ED) and other modern seismic vibration passive control (SVPC) systems, such as shock transmitters (STs) and shape memory alloy devices (SMADs); the number of these applications is increasing more and more. The conclusive influence of earthquake experience and availability and features of the design rules used in each country on the extension of application of the SVPC systems in such a country has been confirmed by the recent data. This paper very briefly summarizes the application of the aforesaid systems worldwide (based on the data provided to the authors by other ASSISi and GLIS members), by stressing the progress of such an application in Italy. Details on this subject may be found, for instance, in the book of Dolce et al. [1].

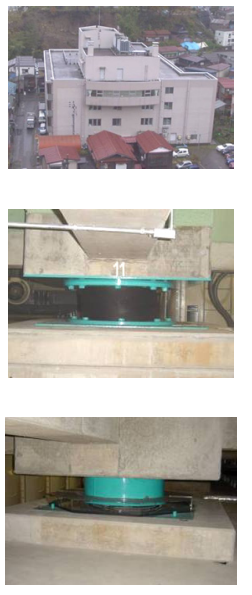

Figure 1: Ojiya City building that withstood the 2004 Mid Niigata quake without any damage; its rubber bearings and SDs.

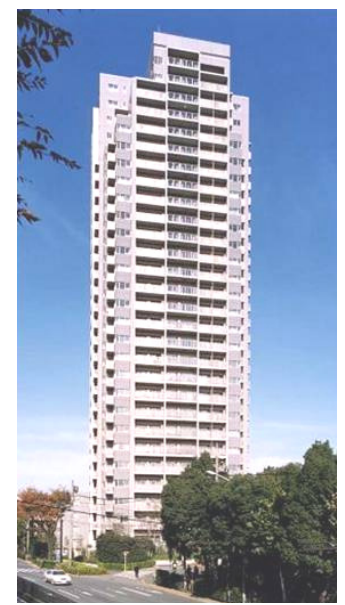

Figure 2: The $87.4 \mathrm{~m}$ high building, which was seismically isolated at Tokyo in 2000 (it was the first Japanese application of SI to high-rise buildings).

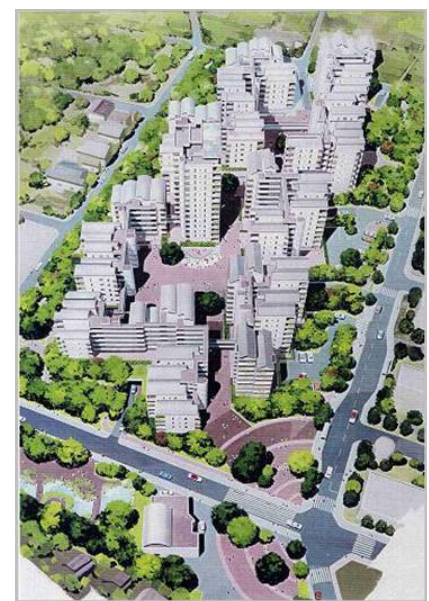

Figure 3: Sketch of the complex of twenty one 6- to 14-storey buildings, all erected on an isolated artificial ground at Sagamihara (Tokyo area) with LRBs, Sliding Devices (SDs) and Ball Bearings.

\section{Application in Japan}

Japan, thanks to the availability of an adequate specific code since 2000 and the free use of SI since 2001, has consolidated its worldwide leadership (with over 3,000 isolated buildings in October 2006), by continuing the extensive adoption of the SVPC systems which had been initiated after the excellent behavior of two isolated buildings near Kobe during 1995 Hygo-ken Nanbu earthquake and was later confirmed by all Japanese isolated buildings struck by subsequent 
earthquakes (fig. 1). In the aforesaid country, where the first application of base SI dates 1985, the trend is now to isolate, on the one hand, even high-rise buildings (fig. 2) and sets of buildings supported by a common isolated reinforced concrete (r.c.) structure (the so called "artificial ground", a solution which enables large savings of construction costs - see fig. 3) and, on the other hand, very small private houses. Furthermore, several Japanese buildings have been protected by various kinds of dampers: for instance, the applications of the Buckling-Restrained Braces (BRBs) were already over 250 in 2003.

Finally, the use of the SVPC systems recently increased in Japan for bridges and viaducts. The latter began there rather later than for buildings; it is being largely based on the use of High Damping Rubber Bearings (HDRBs) and Lead Rubber Bearings (LRBs) and considerably extended especially after the 1995 Hygo-ken Nanbu earthquake (by beginning obligatory for overpasses in Kobe).

\section{Application in the Russian Federation}

The Russian Federation remains second for the number of isolated buildings (550 in June 2005). The use of modern SI systems (namely HDRBs), similar to those adopted in the other countries, is now replacing that of the previous "low cost" isolators, which had been installed since the years 1970s. Recent Russian application includes retrofit of important historical buildings (figs. 4-6) and new designs concern even high-rise buildings.

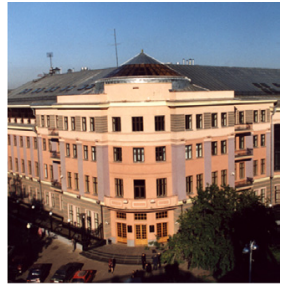

Figure 4: The Irkutsk City Central Bank that was retrofitted with HDRBs.

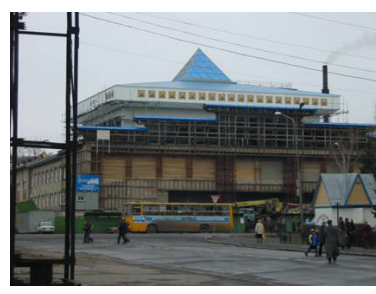

Figure 5: National Drama Theatre at Gorno-Altaisk retrofitted with HDRBs and dampers

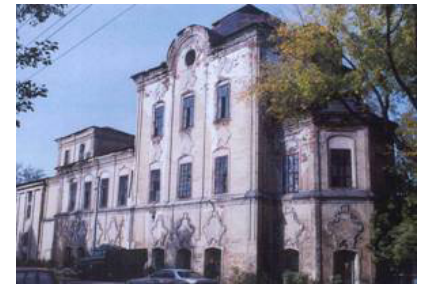

Figure 6: The MihailoArkhangelskaya church at Irtutsk City, which was retrofitted by means of HDRBs.

\section{Application in the People's Republic of China}

Third at worldwide level as to the use of SVPC systems (with 490 isolated buildings, including 270 masonry ones, in June 2005) is the People's Republic of China, where there has been a significant increase of the number of applications for some years, in particular to dwelling buildings (figs. 7 and 8), and large works are going on, such as those concerning the 50 isolated buildings of the new residential center of Peking (fig. 9). In this country there are also very old buildings protected by rough SI systems, but the use of the modern ones began only in 1991. 


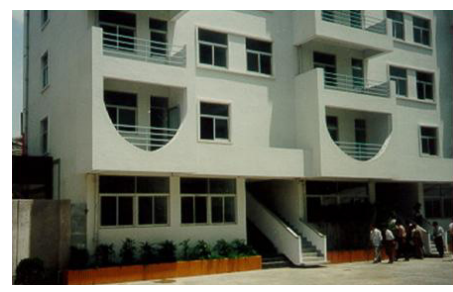

Figure 7: R.c. dwelling building at Shantou that was the first Chinese application of HDRBs (1991). It withstood a significant earthquake with no damage in 1994.

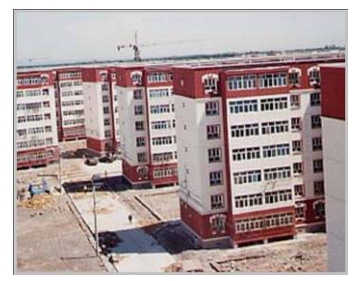

Figure 8: $\quad$ The complex of 60 new masonry dwelling buildings that was erected in Western China with HDRBs in 1996.

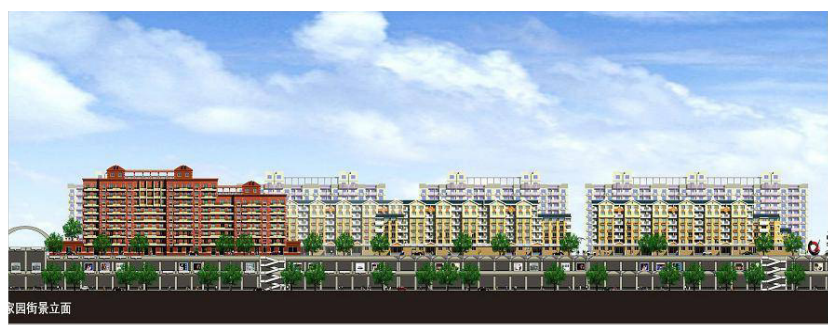

Figure 9: The "Isolation House Building on Subway Hub", the new residential centre of Peking formed by 50 7-9-storey buildings $\left(480,000 \mathrm{~m}^{2}\right)$ supported by a unique 2-storey $(1500 \mathrm{~m} \times 2000 \mathrm{~m})$, containing all facilities and been isolated by means of HDRBs.

\section{Application in the USA}

In the USA, the application of the SVPC systems to bridges and viaducts and, for dampers, also to buildings, is still progressing satisfactorily.

However, in spite of the excellent behavior of some US important isolated buildings during the 1994 Northridge earthquake and long application experience (since 1985), there is now only a limited number of new applications of this kind, due to the very penalizing design code in force for the isolated buildings: according to recent information, the U.S. seismically isolated buildings are now "only" approximately 200, although they are mostly quite important and half of them are retrofits (figs. 10-12). 


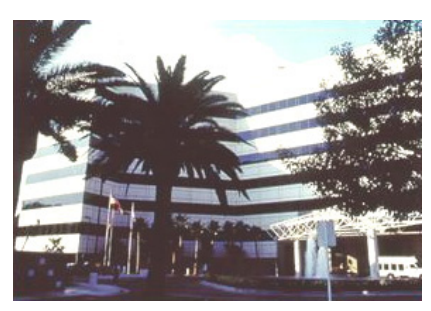

Figure 10: The University of Southern California Hospital at Los Angeles protected by LRBs and completed in 1991, that withstood the 1994 Northridge earthquake without any damage, contrary to other conventionally founded hospitals located in the neighbourhood (e.g. the Olive Hospital, which had just been repaired after suffering severe damage. during the San Fernando earthquake).

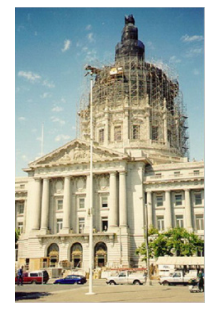

Figure 11: San Francisco City Hall, erected in 1912, which was damaged by the 1989 Loma Prieta earthquake and was seismically retrofitted with 530 LRBs and 62 SDs in 2000 .

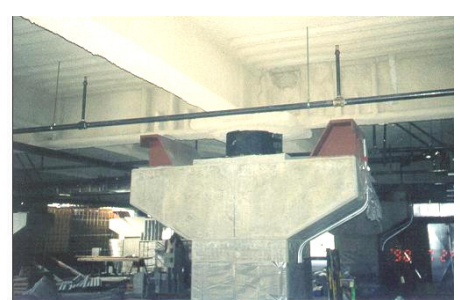

Figure 12: The new 911 Emergency Communications Centre at San Francisco, protected by HDRBs in the years ' 90 s so as to remain fully functional to 8.3 magnitude. This is the design earthquake level for all strategic buildings in California. In any case, also the existing public buildings shall be retrofitted so as withstand very large quakes (e.g. of 8.0 magnitude). This imposes the use of SI, in spite of its large cost in the USA.

\section{Application in Italy}

At present Italy remains fifth for the number of isolated buildings already opened to activity: they are now 43 (fig. 13), in addition to 19 protected by ED systems or SMADs and 28 provided with STs. However, after many years of rather limited use of the SVPC systems (first due to the lack of design rules to the end of 1998, then because of their inadequacy and very complicated and time consuming approval process to May 2003), there is now a significant increase of the number of applications completed in the last biennium (the Italian isolated buildings were 25 in June 2005) and, especially, a large number of new applications in progress or designed (further 44 isolated buildings are already under construction or in an advanced design phase): this occurred thanks to the new Italian seismic code, enforced through Ordinance Nr. 3274/2003 of the Prime Minister (mostly as a consequence of the tragedy of San Giuliano di Puglia during the Molise and Puglia earthquake of October 31, 2002), which frees and simplifies the adoption of the SVPC systems. New applications concern not only strategic and public buildings, including hospitals and schools (figs. 14-18 and 20), but also dwelling buildings (fig. 19) and cultural heritage (figs. 21-25). 


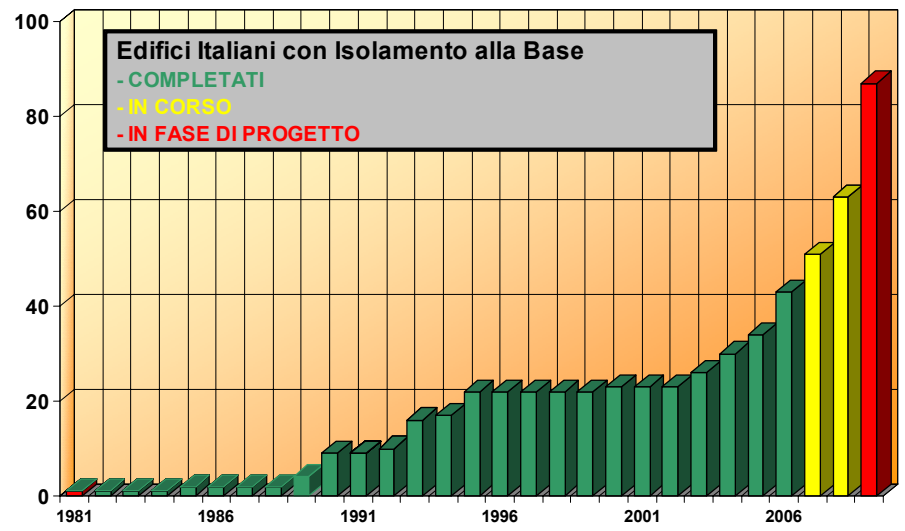

Figure 13: Cumulative number of Italian building applications of SI for the period 1981 to 2006. The very few applications from 1995 to 2003 were due to the absence of adequate design rules.
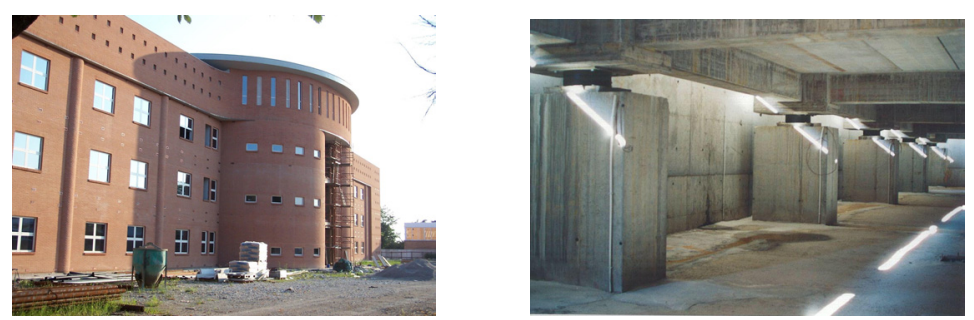

Figure 14: Views of the new wing of Gervasutta Hospital at Udine, which was the first Italian hospital structure to be protected by SI, after its completion and during construction with 56 HDRBs in 2005. All new Italian hospitals being or to be erected in seismic areas now include the SI for earthquake protection.

In addition, Italy remains the worldwide leader as regards the number and importance of bridges and viaducts protected by SVPC systems (they were over 150 already at the beginning of the years 1990s). It is worthwhile reminding that the first application of SI to Italian bridges and viaducts dates 1975 (it was to the Somplago viaduct, which survived the 1976 Friuli earthquake without any damage, contrary to most other structures similarly located in the epicentral area), while the first Italian isolated building was erected in 1981, namely 4 years before the first applications of this kind in Japan and the USA (it concerned a suspended steel-structure fire-command building in Naples that had been conventionally designed before the 1980 Campano-Lucano quake, when the site was not yet seismically classified, and allowed for not fully modifying the original design). 

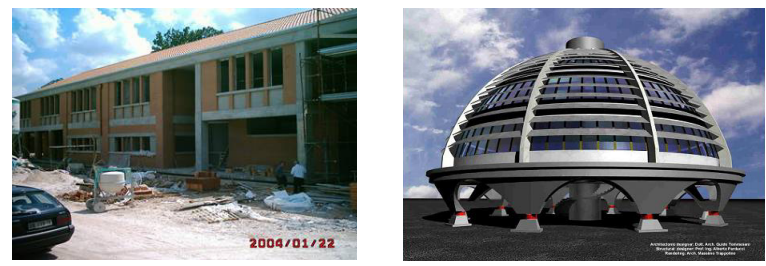

Figure 15: The fire station of the new Civil Defence Centre of Central Italy, completed at Foligno (Perugia) with 52 HDRBs and 5 SDs in 2005. The site of this centre was reclassified to zone 1 in 2003.
Figure 16: The control building of the new Civil Defence Centre being now erected at Foligno with $10 \mathrm{HDRBs}$ of $1 \mathrm{~m}$ diameter (after completion, the Foligno centre will be formed by 13 isolated buildings).

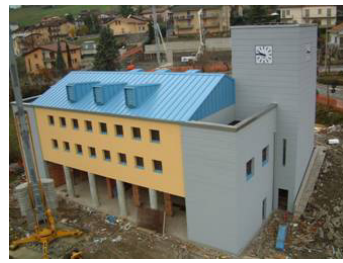

Figure 17: The new Civic Room / Red Cross Headquarters of Gaggio Montano (Bologna, seismic zone 3), quite an irregular structure that was seismically isolated by means of 33 HDRBs and 4 SDs in 2006.

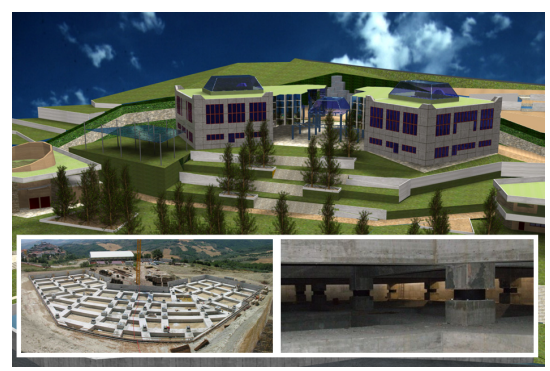

Figure 18: Plastic model of the two buildings of the new Francesco Jovine school being reconstructed at San Giuliano di Puglia, Campobasso (supported by an unique isolated slab), after the collapse of the previous primary school during the 2002 Molise and Puglia earthquake, and view of its SI system, formed by 61 HDRBs and 12 SDs, during construction in 2006-2007.

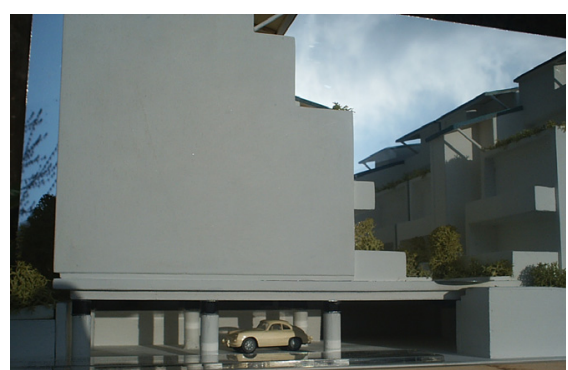

Figure 19: Plastic model of 6 dwelling buildings to be erected on the same artificial ground slab supported by 40 HDRBs and 12 SDs in the framework of the demolition / reconstruction project of the present very degraded Pontecitra 11-buildings complex at Marigliano (Naples). Erection of over 60 buildings on 16 slabs, supported 400-450 HDRBs and 360-380 SDs, has been planned. 

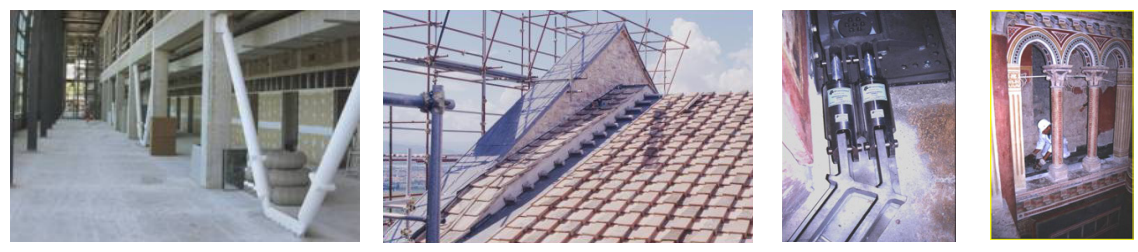

Figure 20: View, dur- Figure 21: Left: some of the 47 SMADs installed in the ing its construction in Upper Basilica of St. Francis at Assisi in 1998-99, 2005, of the new during its restoration after the damages caused by the building of the Poly- 1997-98 Umbria and Marche earthquake, to connect technical University of both tympana to the transept roof. Centre and right: two Marche at Ancona, of the 34 STs installed inside the Upper Basilica, during protected by $86 \mathrm{BRBs}$. the aforesaid restoration, to stiffen it.
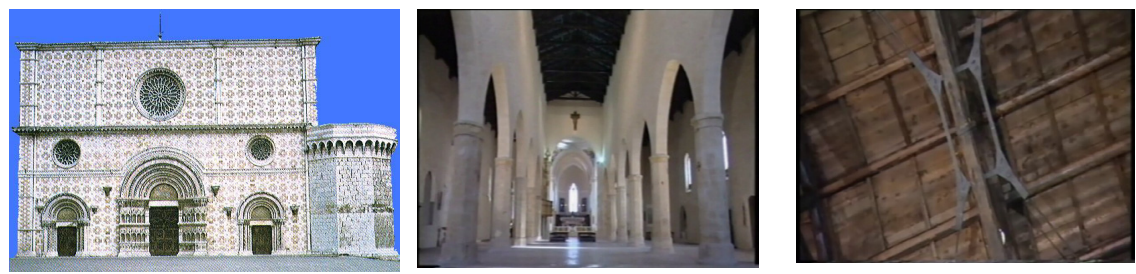

Figure 22: The Cathedral of Santa Maria di Collemaggio at L'Aquila, a unique example of Romanic style in Abruzzo, and view of one of the elastic-plastic dampers (EPDs) installed in its roof after the walls had vibrated during the 199798 Marche and Umbria earthquake, in spite of the very large distance from the epicentre.
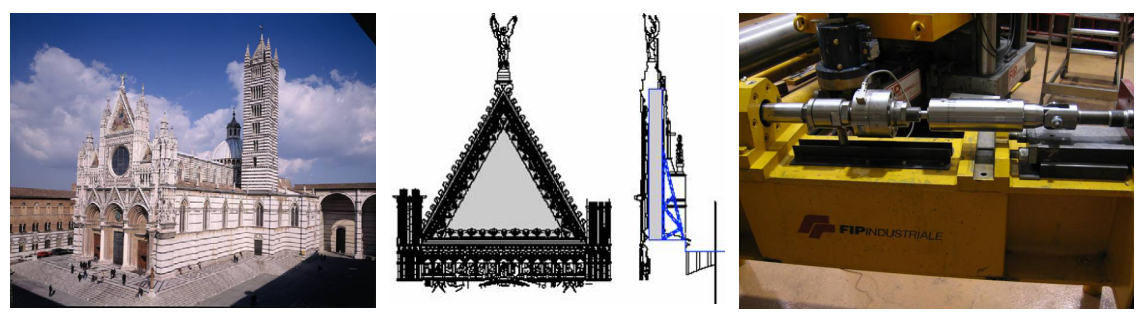

Figure 23: Left and centre: seismic improvement in progress for the Dome of Siena, by means of recentring viscous dampers (VDs), to avoid the overturning of the façade. Right: view of a VD during tests. 


\section{Application in other countries}

As to other countries, of note are the present strong increase of the use of SI and other SVPC systems in Taiwan (after the 1999 Chi Chi earthquake and consequent modification of the seismic code, which now allows for the use of $\mathrm{SI}$ ), the still growing number of isolated buildings in New Zealand (one of the lands of origin of the SVPC systems, in particular those based on lead technology) and, as a consequence of the 1988 Spitak earthquake, also the still developing Armenia, where even significantly high buildings are being seismically isolated and important retrofits have been performed with SI (fig. 27).

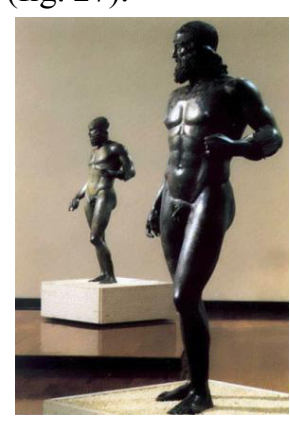

Figure 24: The Bronzes of Riace, each seis-mically isolated by means of a 3-stage HDRB system.
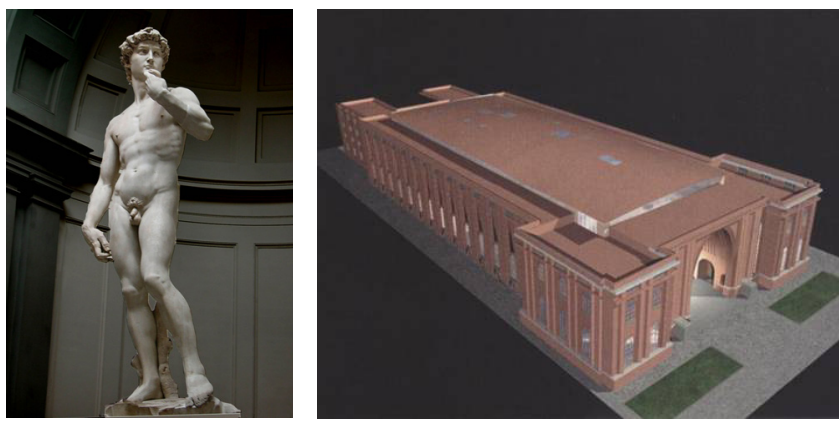

Figure 25: The David of Michelangelo, for which a SI project was undertaken by ENEA, ALGA and the University of Perugia.
Figure 26: The Iran Bastan Museum at Tehran (Iran), for which retrofit by means of SI is being designed in the framework of collaborations between Iran and Italy, which also involve IIEES, ICTP and Italian members of ASSISi and GLIS (the University of Reggio Calabria and ENEA).

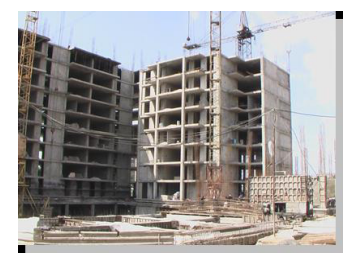

Figure 27: The 16-storey "Our Yard" multifunctional complex, seismically isolated by means of Increased Damping Neoprene Bearings, during its construction at Yerevan (Armenia) in 2006. 
Furthermore, important applications of the SVPC systems also began in Turkey (after the 1999 Kocaeli and Duzce earthquakes, during which the now seismically isolated new Ataturk Istanbul airport, being at that time conventionally constructed, was damaged, while the Bolu viaduct of the Istanbul-Ankara freeway was saved by Italian EPDs), Greece (fig. 29), Portugal (fig. 30) and Cyprus; they are going on in Canada, France (especially in La Martinique island), South Korea, Chile, Mexico and Indonesia and are beginning in other countries (e.g. Iran, see fig. 26). Many of the aforesaid applications (a large part of those in Taiwan, Turkey, Greece, Portugal, South Korea, Cyprus, Indonesia, etc.) make use of SVPC devices manufactured in Italy.

Some more recent Turkish isolated buildings have been protected with LRBs and Low Damping Rubber Bearings (LDRBs).
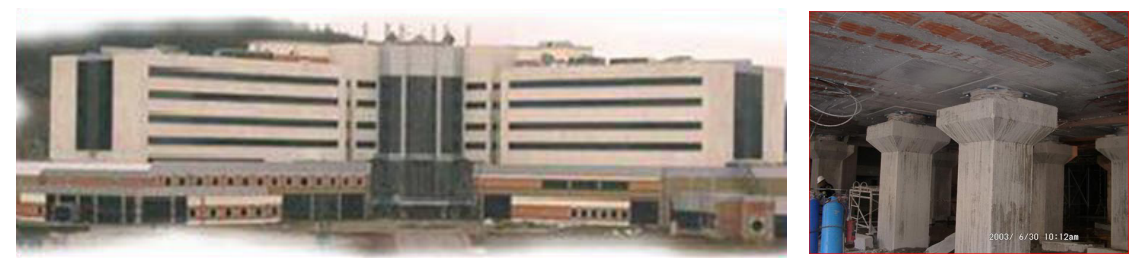

Figure 28: The Kokaeli University Hospital (Turkey), which was seismically isolated with the Friction Pendulum System (FPS) in 2006.

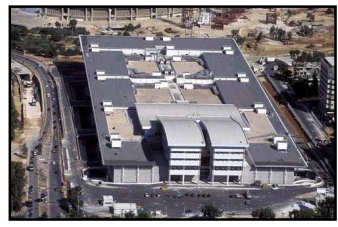

Figure 29: The International Broadcasting Centre at Athens, Greece, isolated with 292 Italian HDRBs in 2003.
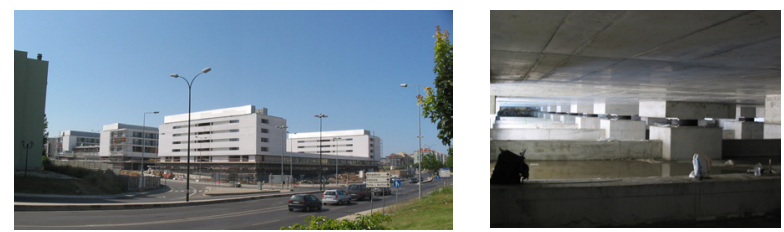

Figure 30: The "La Luz" new hospital at Lisbon (Portugal), which was seismically isolated, together with a residence for old people in 2006; view of some of the 315 HDRBs installed at the buildings base, which were manufactured in Italy.

\section{Application to the cultural heritage}

It is also worthwhile mentioning the already significant application of the SVPC systems to cultural heritage, especially in Italy, including that to monumental structures (e.g. to the Upper Basilica of St. Francis at Assisi, severely damaged by the 1997-98 Marche and Umbria earthquake, see fig. 20), single masterpieces (e.g. the Bronzes of Riace and hopefully, in the near future, David of Michelangelo, see figs. 24 and 25), ceilings of archaeological excavations (e.g. those at Akrotiri, in the Greek Santorini island) and museums. With regard to the latter, the design for retrofitting the Iran Bastan Museum in Tehran with 
seismic isolation is particularly important (fig. 26): this is being developed in the framework of collaborations between Iran and Italy, which also involve the International Institute of Earthquake Engineering and Seismology (IIEES) of Tehran, the Abdus Salam International Centre of Theoretical Physics (ICTP) of Trieste (Italy) and Italian members of $A S S I S i$ and GLIS, affiliated to the Mediterranean University of Reggio Calabria and ENEA.

\section{Application to the industrial structures}

Finally, to be stressed is the increasing use of SI in the industrial field, in particular for high risk plants such as Liquefied Natural Gas (LNG) tanks (e.g. in Turkey and the P.R. China, see figs. 31 and 32, after the first applications performed in Greece and South Korea some years ago) and nuclear structures. Besides the first application of SI to Japanese structures of this kind (the Nuclear Fuel Related Facility, see fig. 33), of note is that the construction of new isolated nuclear reactors has been planned to start soon, both in Japan (where design rules allowing to license them are already available) and in other countries, in particular in France, where SI has already been decided for the Jules Horowitz Reactor and ITER fusion plant, to be both built at the Cadarache Research Centre (characterized by $0.33 \mathrm{~g}$ peak ground acceleration). As to France, it is worthwhile reminding the SI applications to nuclear reactors and spent nuclear fuel storage pools performed at Cruas and La Hague in the years 1970s (in addition to those to civil structures), to allow for the use of standardized plant designs in areas characterized by seismic intensities larger than those considered in such designs.

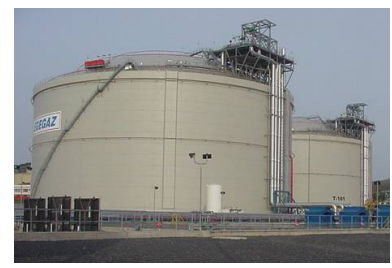

Figure 31: The two $140,000 \mathrm{~m}^{3}$ LNG tanks of Egegaz at Aliaga, Turkey, protected by 112 LRBs and 241 LDRBs.

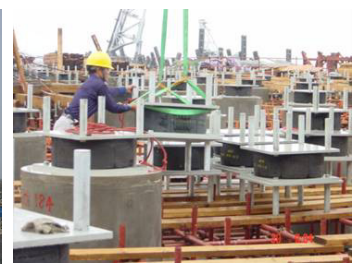

Figure 32: The two $160,000 \mathrm{~m}^{3}$ LNG tanks at Guandong (P.R. China), each with 360 HDRBs in 2006.

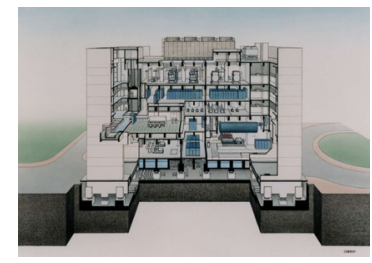

Figure 33: The Nuclear Fuel Related Facility, which was the first nuclear structure to be seismically isolated in Japan.

\section{Conclusions}

The state-of-the-art of the application of the modern seismic vibration passive control (SVPC) techniques has been shortly reported, especially for seismic isolation (SI) of buildings. Particular attention has been devoted to the use of the 
SVPC systems in Italy, by showing the leadership it achieved in this field at European level, in spite of the problems suffered until four years ago (first due to the absence of specific design rules, then owing to their inadequacy and the too complicated approval process). It is worthwhile mentioning that the contributions provided by ENEA have been of fundamental importance for the development and application of the SVPC systems in Italy. The present excellent prospects for a wide extension of the use of such systems in our country, thanks to the new national seismic code and the seismic reclassification of the Italian territory, have been stressed. More generally, the key role plaid by the availability and features of specific design rules on the success of the aforesaid systems in the different countries has been cited.

\section{References}

[1] Dolce, M., Martelli, A., and Panza, G. 2006. Moderni Metodi di Protezione dagli Effetti dei Terremoti (Modern Methods for the Protection from Earthquake Effects), Special edition for the Italian Civil Defense Department, A. Martelli, ed., $21^{\text {mo }}$ Secolo: Milan, Italy (in Italian). 